\title{
Using primate models to study the evolution of human locomotion: concepts and cases
}

\author{
Apport des modèles primates à l'étude de l'évolution de la locomotion humaine : \\ concepts et exemples
}

\author{
K. D'Août · P. Aerts · G. Berillon
}

Received: 05 February 2014; Accepted: 04 March 2014

(C) Société d'anthropologie de Paris et Springer-Verlag France 2014

\begin{abstract}
This note introduces the types of models used in functional morphological research in order to clarify certain semantic issues and to present some examples of the use of extant model species to contribute to our understanding of bipedal locomotion. The existing models fall into two broad categories: "abstraction models" are simplifications/ abstractions of living organisms, whereas "comparative models" are extant organisms used as models or analogues for other organisms (e.g. extinct species). In a palaeoanthropological context, comparative models may be selected for their close (but always imperfect) resemblance to the organism of interest, but some atypical model species can also produce insights not despite their imperfect resemblance, but because of it. We present three examples of our own work on comparative primate models during studies of terrestrial bipedal locomotion in bonobos (Pan paniscus), olive baboons (Papio anubis), and white-handed gibbons (Hylobates lar), showing how they each provide insights into the evolution of human bipedal locomotion.
\end{abstract}

Keywords Locomotion $\cdot$ Bipedal $\cdot$ Models $\cdot$ Non-human primates

\section{K. D'Août ( $\square)$}

Department of Musculoskeletal Biology,

Institute of Ageing and Chronic Disease, University of Liverpool,

Duncan Building, Daulby Street, Liverpool L69 3GA, UK

e-mail : Kristiaan.Daout@liverpool.ac.uk

K. D'Août $\cdot$ P. Aerts

Department of Biology, University of Antwerp,

Universiteitsplein 1, 2610 Antwerpen, Belgium

P. Aerts

Movement and Sports Sciences, University of Ghent,

Watersportlaan 2, 9000 Gent, Belgium

G. Berillon

UPR 2147 CNRS, 44, rue de l'Amiral Mouchez,

75014 Paris, France
Résumé Cette note introduit les types de modèles issus de la morphologie fonctionnelle dans le but de clarifier certaines confusions sémantiques et présente quelques cas d'étude contribuant à une meilleure connaissance de la locomotion bipède. Deux vastes catégories de modèles existent : les modèles abstraits, qui sont une simplification et une abstraction d'organismes vivants, et les modèles comparatifs qui sont des organismes vivants utilisés comme modèles/analogues d'autres organismes (p. ex. espèces disparues). Dans une perspective paléoanthropologique, à côté de l'approche qui cherche le meilleur (mais toujours imparfait) « remplaçant » de l'espèce fossile étudiée, l'étude de modèles, atypiques, peut aussi nous apprendre beaucoup du fait de leur imparfaite ressemblance à l'espèce étudiée. Nous présentons trois exemples d'études de modèles primates issues de nos propres travaux sur la bipédie, le babouin olive (Papio anubis), le gibbon à mains blanches (Hylobates lar), et le bonobo (Pan paniscus), en montrant en quoi ils permettent de mieux comprendre certains aspects de l'évolution de la locomotion humaine.

Mots clés Locomotion · Bipède $\cdot$ Modèles $\cdot$ Primates non humains

\section{Introduction}

Among living primates, habitual bipedal locomotion is unique to humans, and is used as a defining characteristic for hominins (e.g. [1]). This locomotor mode has been associated with a range of anatomical features (e.g. [2]) but is also considered to be crucial in the cognitive development of hominins $[3,4]$. Therefore, and unsurprisingly, bipedal locomotion has been studied intensively.

Bipedal locomotion in modern humans (Homo sapiens) can be studied relatively easily, thanks to the availability of gait laboratories equipped with a suite of tools for studying kinematics (e.g. marker-based 3D systems), kinetics 
(e.g. force plates and pressure pads), and control (e.g. electromyography). Such studies provide insights into proximate aspects of gait, i.e., how does a gait work? However, gaining such proximate insights into the gait of extinct species is not possible in a direct way: what we can do, and therefore what we can learn, is greatly limited by our incomplete understanding of the hominin timeline, and by difficulties in interpreting fossils (i.e. skeletal remains and fossilised footprints), which are very incomplete representations of the organism they belonged to. Furthermore, we are not only interested in proximate understanding, but also in ultimate [5] causes: how and why did habitual bipedalism evolve?

Answering this question is by no means simple, because our image of the hominin timeline is evolving and becoming more complex as new fossils are discovered. It can be assumed that with new discoveries, and especially with genetic and biogeographical advances, our insight into which species were ancestral to us, and what they looked like, will continue to grow but, most probably, will always remain incomplete.

Recent findings show that inferring functional correlates about a species' lifestyle may be even more complex than initially thought. Two examples that illustrate this are, on the one hand, the presence of "derived" features suggesting bipedalism in a Miocene ape, Oreopithecus ([6], but see [7]), and on the other hand, the possible presence of "primitive" features relatively recently (3.4 mya, [8]; 2-6-2.0 mya, [9]) and even currently, e.g. a "midfoot" break in the human foot (e.g. $[10,11])$.

Recent paleontological discoveries (e.g. well preserved and fairly complete skeletons) demonstrate the bushy nature and wide variation in locomotor anatomy during hominin evolution. Even though our human bipedalism is unique among extant primates, a variety of bipedal modes that differed from ours, but were also successful, have probably existed (e.g. [8,12-14]). Therefore, focusing exclusively on modern humans as having the sole solution to habitual bipedal locomotion seems too restrictive.

Due to the large number of new fossil discoveries, often with a puzzling anatomy, it has become even more important to try to fully understand form-function relationships. As stated previously, this cannot be done directly in the case of early bipedal locomotion, and therefore has to be done indirectly, by using models.

The aim of this note is to outline the types of models that exist in the field of functional morphology, in an attempt to clarify existing semantic confusion, and to present a few examples of how model studies are advancing our understanding of bipedal locomotion.

\section{Concepts}

Usage of the term «model» in a functional anatomical context falls into two broad categories that we can term "abstraction models" and "comparative models".
In the first category, the model is an abstraction and a simplification of the living organism. This type of model can take different forms [15], from the purely conceptual (e.g. the inverted pendulum paradigm for walking), to the mathematical (e.g. a software implementation of the inverted pendulum) and the physical (e.g. McGeer's passive dynamic walkers [16]). This type of model should, by definition, be relatively simple - if not, we run the risk of not understanding its fundamentals any more easily than when we use the real animal. If successful, the model will produce insights into basic principles.

In the second category - comparative models - living organisms are used as models/analogues for other living organisms. There are two main reasons for using this approach: either because the species of interest is an extant species that cannot be studied for ethical or practical reasons (which is the case in biomedical research, hence the use of rodents, for example), or because the species of interest is extinct. The latter is the case in palaeoanthropological research.

One issue with this type of model is that it does not simplify biological reality and therefore remains complex to study and understand. The solution, in an attempt to find general insights, is to use multiple models and to infer general "rules" by finding common denominators between the species studied.

It should be stressed that the two types of models outlined here are not mutually exclusive (they have their respective strengths and weaknesses) and can be combined in multidisciplinary work. For instance, abstraction models (e.g. simple robots) can be used to test ideas gathered from the use of comparative models, but a biological model can also stimulate progress in the design of abstraction models, e.g. in bioinspired robotics (Fig. 1).

The use of comparative models in palaeoanthropological research is the focus of the present conceptual note, as it presents specific challenges. Whereas many ecological morphological studies use very large data sets (many species, many individuals and relatively low-tech data such as basic morphometrics) and can thus unleash the full potential of the comparative approach by using phylogeny-aware analysis methods (e.g. [17,18] palaeoanthropological research is more limited. In most cases, the number of species and individuals is low: the fossil record is still very limited, and extant study species are often primates that cannot be studied in very large numbers. In the latter case, achieving the goals of the comparative method can only be a long and gradual process, and will involve meta-analyses of multiple studies on different species.

Given these practical issues, a very relevant question is 'which species should be selected as comparative models?'

In the literature, a substantial body of work has focused on determining the "best" model to use for increasing our understanding of the evolution of bipedalism. Typically, in 


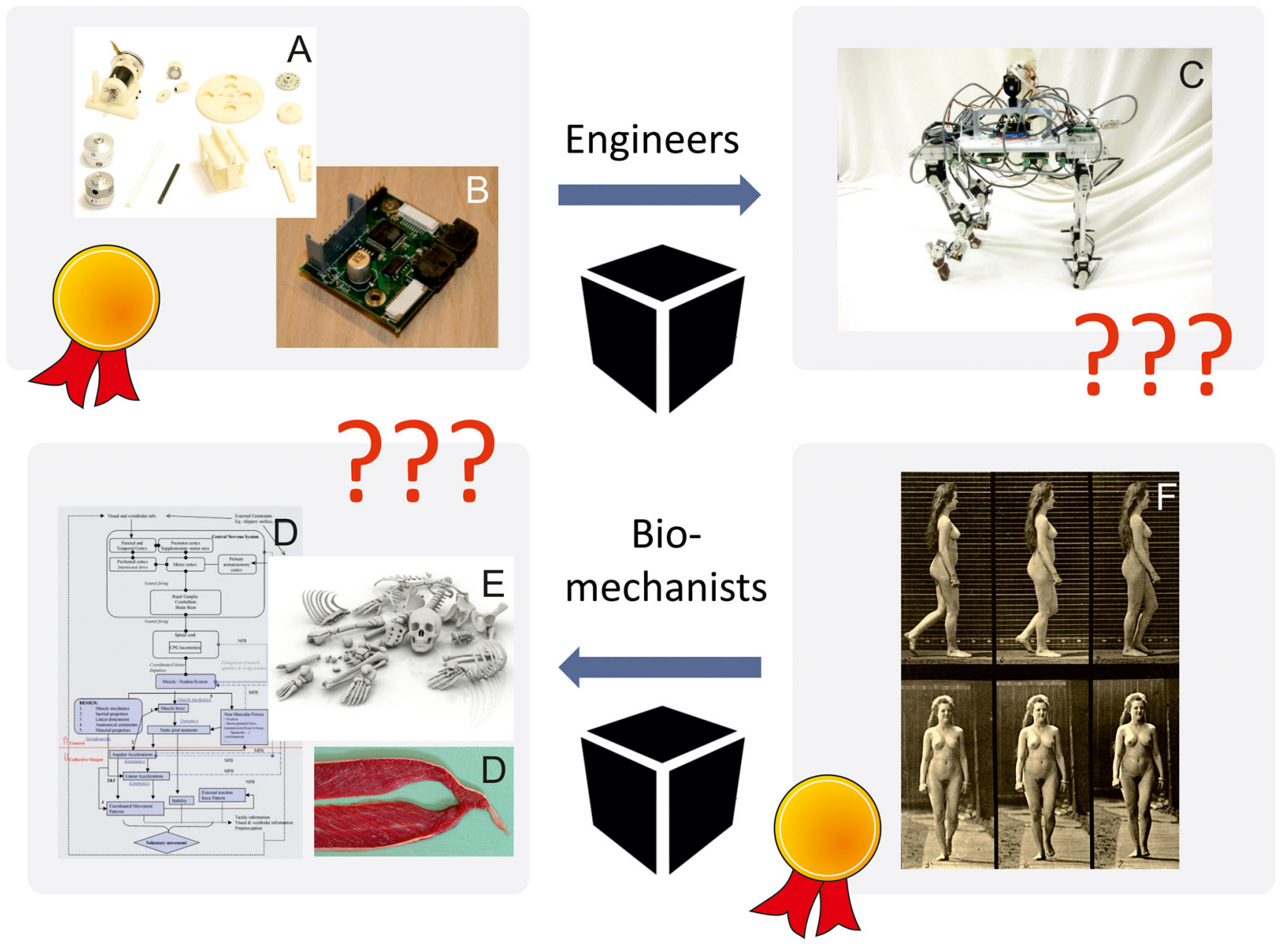

Fig. 1 Conceptual diagram. Engineers (top row) start from hardware and control algorithms they understand well (man-made, A, B), and the challenge is to make something truly functional out of these parts $(\mathrm{C})$. This process is the challenge (thus far, machines underperform compared to animals except for very specific tasks) and is still a "black box" to a large extent. Biomechanists (bottom row) have the opposite problem. They start from systems that work very well (living organisms, F) and they want to understand the "hardware and algorithms" (i.e. morphology and control, D-E) that make it all work. This is also difficult, and also largely a "black box". In both approaches, the "black box" is in fact the same, and tackling it from both sides will open it most easily. These two examples relate to abstraction models and comparative models, respectively. (Image credits: A-C: www.locomorph.eu; D: Laboratory for Functional Morphology, University of Antwerp; E: David Castillo Dominici / FreeDigitalPhotos.net; F: www.muybridge.org) / Schéma conceptuel. Les ingénieurs (ligne du haut) commencent avec du matériel et des algorithmes de contrôle qu'ils connaissent bien (fabriqués par l'homme, $A, B)$, le challenge est de réaliser quelque chose de réellement fonctionnel à partir de ces composantes (C). Ce processus est le challenge (de loin, les machines sont peu performantes en comparaison des animaux, excepté pour des tâches très spécifiques) et représente une boîte noire pour la plupart. Les biomécaniciens (ligne du bas) ont un problème inverse. Ils partent d'un système qui fonctionne très bien (organismes vivants, $F$ ) et ils veulent comprendre le "matériel et les algorithmes » (i.e. la morphologie et le contrôle, D-E) qui le font fonctionner. Ceci est également difficile, et largement une boîte noire. Dans les deux approches, la boîte noire est en fait la même, et l'aborder des deux côtés l'ouvrira plus facilement. Ces deux modèles concernent des modèles abstraits et comparatifs respectivement. (Crédits illustrations: A-C: www.locomorph.eu ; D : Laboratory for Functional Morphology, University of Antwerp; E : David Castillo Dominici / FreeDigitalPhotos.net; F: www.muybridge.org).

this quest, various arguments are put forward for the "best stand-in" for a fossil species. These arguments can be phylogenetic, in which case apes of the Pan genus, chimpanzees and bonobos, are considered to be the best because they are most closely related to hominins (e.g. $[19,20])$. The arguments can also be morphological (e.g. bonobos are better "Australopithecus" models than chimpanzees, [21], but see also [22]), behavioural (orang-utan-like orthograde 
scrambling as a model for early hominin locomotion [23]) or related to the palaeo-environment [24].

Each of these models has been (and continues to be) highly instructive in its own right, but they are not perfect "stand-ins" as none of the extant taxa closely resembles the last common ancestor of living apes and humans (e.g. [25]). With the continuing discovery of new fossils, it is not even clear which species these models should try to approach. A good example is the case of Australopithecus afarensis, which was long regarded as the focal species in the evolution of human bipedalism. However, with recent findings and evidence of bipedal adaptations in older hominins such as Sahelanthropus tchadensis [26], Orrorin tugenensis [27] and Ardipithecus ramidus [28, 29], this view of Australopithecus afarensis, while still a very interesting species, has become more nuanced.

Regardless of the (widely acknowledged) "imperfections" of the models, they have enabled specific hypotheses to be tested in many cases and have thus brought new insights into the evolution of bipedalism and the selective pressures involved. One example is that in terms of energy, there is no advantage in bipedalism over quadrupedalism in chimpanzees [30,31]. Even if early hominins were not exactly chimpanzee-like, this result is useful when evaluating the energy-saving hypothesis of hominin bipedalism [32].

We suggest that, since no single comparative model can be a "perfect stand-in", the selection of the study species should not merely attempt to mimic the species of interest (even if known), but should also be based on factors other than physical or behavioural resemblance.

In this context, we suggest that there is great promise for a group of models that does exactly the opposite of the "standin" type, namely, models that are atypical and can teach us a lot - not despite their imperfect resemblance, but because of it. Obviously, one expects baboons to be good quadrupeds, or gibbons to be good brachiators, because they display numerous relevant adaptations. But why is it, against all odds from a mechanistic point of view, that gibbons display good terrestrial bipedal locomotion and quadrupeds such as baboons can be adept bipeds?

Such models can be seen as test cases (and useful outgroups, e.g. [33]), and by understanding exceptions to the rules, we may understand the rules better, much as clinical studies of diseases (even the rarest ones) can push our understanding of the healthy body forward.

We will now present a few examples of different models, from our own work and from the literature, in which these two types of comparative models have been used, and show how they have advanced our understanding of the evolution of human locomotion.

\section{Cases}

\section{Bipedal baboons}

Baboons are described as highly specialized anatomically to terrestrial quadrupedal locomotion (e.g. [34]). Terrestrial bipedal behaviour represents a very small component of their locomotor and positional repertoire both in the wild ([35,36]) and in captivity [37] compared to African hominoids (e.g. [38]). However, experiments with an ontogenetic sample of untrained olive baboons (Papio anubis) have demonstrated that with regard to joint angles, baboons walk bipedally in a constant and well-coordinated manner, with flexed hips and knees and a slightly bent trunk [39], as do other non-human primates (see below), albeit with some peculiarities in the type of foot contact to the ground and in forelimb posture and motion [40]. Recent experiments, including muscle activation of the hind limbs as well as kinetics measurements, corroborate these conclusions [41]. Terrestrial bipedal walking in olive baboons must therefore be seen as a locomotor mode in itself and not as a random pattern, even though these primates are adapted to a different mode of locomotion. Similar conclusions based on different experiments (for example the mechanics of the gibbon's foot) can be drawn for other anthropoids adapted to different locomotor modes (see below). This allows us to suggest that the same may hold true for the last common ancestor of humans and African hominoids as well as for the very early hominins, in which terrestrial bipedalism should be seen as an efficient mode of locomotion even though there are few derived traits in their anatomy but many others that would be better suited to arboreal habits $[12,27]$.

\section{Terrestrial gibbons}

Ground reaction forces, plantar pressure data and detailed foot kinematics were collected (spatially and temporally) during terrestrial bipedal walking of white-handed gibbons (Hylobates lar). By combining this quantitative information with morphological data, we calculated instantaneous external joint moments and forces at the highly mobile metatarso-phalangeal, tarso-metatarsal and talo-crural joints [42]. This produced new insights into the propulsion-generating capacities of the internal foot joints. Despite its high compliance, the gibbon foot clearly generates propulsion in bipedal locomotion via stretching and recoil of the plantar flexor tendons and plantar ligaments. Hence, the "rigid" arched foot of modern humans (but see earlier) does not seem to be an exclusive prerequisite for more efficient bipedal locomotion through energy saving mechanisms, a finding that may shed a new light on the walking efficiency of our early ancestors [42]. 


\section{Terrestrial bonobos}

Spatio-temporal gait characteristics and planar segmental kinematics of quadrupedal and bipedal locomotion over a range of speeds were studied in bonobos (Pan paniscus) in order to highlight differences and/or similarities in motor behaviour $[43,44]$. It appears that, when normalized for size and although they are different in magnitude, quadrupedal and bipedal strides, step lengths and stride frequencies each relate in an identical exponential way to speed in both locomotor modes. This strongly suggests that modulation of walking speed is controlled independently of pedality (i.e., quadrupedal or bipedal) [43]. Moreover, kinematic patterns throughout the stride of the hind limb joints (hind limbs are also the main propulsive limbs in the quadrupedal mode) are very similar for quadrupedal and bipedal walking. The only difference is that the hip oscillates around a larger average value when walking is bipedal, which is related to the more upright posture of the trunk in the latter mode [44]. Together, these findings strongly suggest that acquisition of a bipedal locomotor mode through a 'quadrupedal bauplan' does not necessarily require large adaptations in coordination and control [45]. From an evolutionary perspective, this tends to support hypotheses suggesting that optional bipedal, or at least orthograde, locomotor behaviour may well have preceded obvious morphological human-like adaptations (e.g. [46]).

\section{Conclusion}

In conclusion, different types of models obviously serve different purposes, but it is clear that functional studies on carefully selected extant species, in a comparative context, can greatly improve our understanding of form-function relationships - not only in these species themselves, but also in extinct species. Finally and more broadly, this is also true for any of the main human functions.

\section{References}

1. Wood B (2000) Investigating human evolutionary history. J Anat 197:3-17

2. Aiello LC, Dean C (1990) An introduction to human evolutionary anatomy, London, Academic Press, $596 \mathrm{p}$

3. Aiello LC (1996) Terrestriality, bipedalism and the origin of language, Oxford (UK), Oxford University Press, $300 \mathrm{p}$

4. Zehr EP, Hundza SR (2009) The quadrupedal nature of human bipedal locomotion. Exerc Sport Sci Rev 37(2):102-8

5. Mayr E (1961) Cause and effect in biology. Science 131:1501-06

6. Köhler M, Moyà-Solà S (1997) Ape-like or hominid-like? The positional behavior of Oreopithecus bambolii reconsidered. Proc Natl Acad Sci USA 94(21):11747-50
7. Susman RL (2005) Oreopithecus: still apelike after all these years. J Hum Evol 49(3):405-11

8. Haile-Selassie Y, Saylor BZ, et al (2012) A new hominin foot from Ethiopia shows multiple Pliocene bipedal adaptations. Nature 483(7391):565-9

9. DeSilva JM, Proctor DJ, et al (2012) A complete second metatarsal (StW 89) from Sterkfontein Member 4, South Africa. J Hum Evol 63(3):487-96

10. Bates KT, Collins D, et al (2013) The evolution of compliance in the human lateral mid-foot. Proc R Soc Lond B Biol Sci 280 (1769)

11. DeSilva JM, Gill SV (2013) Brief communication: A midtarsal (midfoot) break in the human foot. Am J Phys Anthrop 151 (3):495-99

12. White TD, Asfaw B, et al (2009) Ardipithecus ramidus and the paleobiology of early Hominids. Science 326(5949):75-86

13. Berger LR (2013) The mosaic nature of Australopithecus sediba. Science 340(6129):163-63

14. Lieberman DE (2012) Those feet in ancient times. Nature 483 (7391):550-51

15. Alexander RM (2003) Modelling approaches in biomechanics. Philos Trans R Soc Lond B Biol Sci 358(1437):1429-35

16. McGeer $T$ (1990) Passive dynamic walking. Int J Robot Res 9 (2):62-82

17. Felsenstein J (1985) Phylogenies and the comparative method. Am Nat 125(1):1-15

18. Harvey PH, Pagel MD (1991) The comparative method in evolutionary biology, Oxford, Oxford University Press, $239 \mathrm{p}$

19. Goodman M, Porter CA, et al (1998) Toward a phylogenetic classification of primates based on DNA evidence complemented by fossil evidence. Mol Phylogenet Evol 9(3):585-98

20. Perelman P, Johnson WE, et al (2011) A molecular phylogeny of living primates. Plos Genet 7(3):e1001342

21. Zihlman AL, Cronin JE, et al (1978) Pygmy chimpanzee as a possible prototype for common ancestor of humans, chimpanzee and gorillas. Nature 275:744-46

22. Corruccini RS, McHenry HM (1979) Morphological affinities of Pan paniscus. Science 204(4399):1341-3

23. Thorpe SKS, Holder RL, et al (2007) Origin of human bipedalism as an adaptation for locomotion on flexible branches. Science 316(5829):1328-31

24. Kano T (1992) The last ape: pygmy chimpanzee behavior and ecology, Stanford, Stanford University Press, $276 \mathrm{p}$

25. Almécija S, Tallman M, et al (2013) The femur of Orrorin tugenensis exhibits morphometric affinities with both Miocene apes and later hominins. Nat Commun 4:2888

26. Brunet M, Guy F, et al (2002) A new hominid from the Upper Miocene of Chad, Central Africa. Nature 418:145-51

27. Senut B, Pickford M, et al (2001) First hominid from the Miocene (Lukeino Formation, Kenya). C R Acad Sci Paris IIa 332(2):137-44

28. White TD, Suwa G, et al (1994) Australopithecus ramidus, a new species of early hominid from Aramis, Ethiopia. Nature 371:306-12

29. Lovejoy CO, Suwa G, et al (2009) The pelvis and femur of Ardipithecus ramidus: The Emergence of Upright Walking. Science 326(5949)

30. Sockol MD, Raichlen DA, et al (2007) Chimpanzee locomotor energetics and the origin of human bipedalism. Proc Natl Acad Sci USA 104(30):12265-69

31. Pontzer H, Raichlen DA, et al (2014) Bipedal and quadrupedal locomotion in chimpanzees. J Hum Evol 66: 64-82.

32. Rodman PSMcHenry HM, et al (1980) Bioenergetics and the origin of Hominid bipedalism. Am J Phys Anthrop 52:103-06

33. Lemelin P (1999) Morphological correlates of substrate use in didelphid marsupials: implications for primate origins. J Zool 247:165-75 
34. Fleagle JG (1999) Primate adaptation and evolution (Second Edition), San Diego, Academic Press, 596 p

35. Hunt K (1991) Positional behavior in the Hominoidea. Int J Primatol 12(2):95-118

36. Rose MD (1976) Bipedal behavior of Olive baboons (Papio anubis) and its relevance to an understanding of the evolution of human bipedalism. Am J Phys Anthrop 44:247-62

37. Druelle F, Berillon G (2013) A bipedal behaviour in Olive baboons: infants versus adults in a captive environment. Folia Primatol 84(6):347-61

38. Doran DM (1989) Chimpanzee and pygmy chimpanzee positional behavior: The influence of environment, body size, morphology, and ontogeny on locomotion and posture, State University of New York at Stony Brook, $329 \mathrm{p}$

39. Berillon G, D'Août K, et al (2011) In what manner do quadrupedal primates walk on two legs? Preliminary results on Olive baboons (Papio anubis). In D'Août K, Vereecke E (eds) Primate Locomotion: Linking Field and Laboratory Research. Springer, New York, pp 61-82

40. Berillon G, Daver G, et al (2010) Bipedal versus quadrupedal hind limb and foot kinematics in a captive sample of Papio anubis: setup and preliminary results. Int J Primatol 31(2):159-80
41. Berillon G, Molina Vila P, et al (2013) Biomechanics and control of walking in Olive baboons (Papio anubis): new perspectives from trained and instrumented animals. Folia Primatol 84:249

42. Vereecke EE, Aerts P (2008) The mechanics of the gibbon foot and its potential for elastic energy storage during bipedalism. J Exp Biol 211(23):3661-70

43. Aerts P, Van Damme R, et al (2000) Spatio-temporal gait characteristics of the hind-limb cycles during voluntary bipedal and quadrupedal walking in Bonobos (Pan paniscus). Am J Phys Anthrop 111:503-17

44. D'Août K, Aerts P, et al (2002) Segment and joint angles of hindlimb during bipedal and quadrupedal walking of the Bonobo (Pan paniscus). Am J Phys Anthrop 119(1):37-51

45. Nishikawa K, Biewener AA, et al (2007) Neuromechanics: an integrative approach for understanding motor control. Integr Comp Biol 47(1):16-54

46. Crompton RH, Vereecke EE, et al (2008) Locomotion and posture from the common hominoid ancestor to fully modern hominins, with special reference to the last common panin/hominin ancestor. J Anat 212(4):501-43 